further chest radiograph showed only a small residual pleural effusion.

\section{Discussion}

Invasive actinomycosis affects the cervicofacial region in $65 \%$ of cases, the abdomen in $20 \%$ of cases, and the thorax in only $15 \%$ of cases. Thoracic actinomycosis is rare in childhood; we could find only two reports of its occurrence in the United Kingdom. ${ }^{12}$ Lack of familiarity with the disease by both clinicians and radiologists may, however, lead to diagnostic error.

Actinomyces is a normal commensal of the human mouth. Pulmonary actinomycosis may result from infection from several sourcesaspiration from the oral cavity, carriage into the lung on a foreign body, haematogenous seeding, or spread of existing cervicofacial or abdominal infection through the tissue planes. ${ }^{3}$ Actinomyces are Gram positive, non-acid fast bacilli, and are facultative anaerobes. They are true bacteria, although they were previously classified with fungi because of their mycelial appearance and indolent clinical course. $A$ israelii is the most common species, although there are others such as Actinomyces meyerii that can cause similar disease.

The clinical features in this case are characteristic of actinomycosis. Actinomyces infections do not respect tissue planes; the complex of pulmonary, pleural, and chest wall disease is unusual with other infections. ${ }^{4}$ Actinomycosis is rare in normal children, because dental caries or peridontitis are usually followed by rapid loss of the teeth. ${ }^{5}$ It is more common in immunocompromised children, or among mentally subnormal children in institutions, ${ }^{2}$ where poor dentition is common.

Diagnosis is often delayed because of failure to consider actinomycosis, and the difficulty in obtaining specimens and culturing them anaerobically. Examination of pus may show sulphur granules, which are suggestive but not diagnostic of actinomycosis. Microscopic examination shows Gram positive branching filaments with terminal clubs, but often the organism is not seen after anaerobic culture. Recovery of the organism from sputum means nothing, as it is a normal oral commensal. The classic radiological presentation of thoracic actinomycosis is the triad of chronic consolidation, pleural effusion, and overlying rib periostitis as was seen in this case. ${ }^{2}$ Periostitis indicates chronic infection, rather than destruction by acute infection or malignancy. Computed tomography is useful in evaluating the lesion. ${ }^{6}$ The differential diagnosis is wide, and includes tuberculosis, lung abscess, carcinoma, reticulosis, and atypical pneumonia. ${ }^{35}$

The use of antibiotics in the treatment of actinomycosis has resulted in a high rate of cure, even in advanced disease, and the most appropriate drug is penicillin. ${ }^{3}$ There is no agreement, however, about dosage or duration of treatment. Parenteral penicillin is usually given for several weeks, followed by penicillin orally for three to six months. In some centres high doses of oral penicillin alone have been used. ${ }^{4}$ Other antibiotics have also been used successfully, including erythromycin, chloramphenicol, clindamycin, and lincomycin, particularly in cases of allergy to penicillin.

Prognosis is excellent when diagnosis has been reached and specific antibiotics used. Mortality in the past was related to late diagnosis, haematogenous spread, and injudicious surgical intervention.

1 Drake DP, Holt RJ. Childhood actinomycosis. Report of three recent cases. Arch Dis Child 1976;51:979-81.

2 Thompson AJ, Carty $\mathbf{H}$. Pulmonary actinomycosis in children. Pediatr Radiol 1979;8:7-9.

3 Medoff G, Kobayashi G. Pulmonary infections due to actinomyces and nocardia, and pulmonary mycoses. In: Reigin RD, Cherry ID eds. Textbook of pediatric infections Reigin RD, Cherry JD, eds. Textbook of pediatric infectious diseases. 2nd Ed. Philadelphia: WB Saunders, 1987:300-2. acic actinomycosis. Pediatr Infect Dis 1986;5:594-5.

5 Bennhoff DF. Actinomycosis: diagnostic and therapeutic considerations and a review of 32 cases. Laryngoscope 1984; 94:1198-217.

6 Golden N, Cohen $H$, Weissbrot J, Silverman S. Thoracic actinomycosis in childhood. Clin Pediatr 1984;24:646-50.

\title{
Spontaneous resolution of congenital nephrotic syndrome in a neonate
}

\author{
C R Banton, B Thalayasingam, M G Coulthard
}

\section{Shotley Bridge \\ General Hospital, Consett, \\ Co Durham \\ C R Banton \\ B Thalayasingam \\ Royal Victoria Infirmary, Newcastle upon Tyne \\ NE1 4LP \\ M G Coulthard \\ Correspondence to: Dr Coulthard.}

Accepted 24 April 1990

(Arch Dis Child 1990;65;992-3).

\begin{abstract}
An infant with congenital nephrotic syndrome recovered spontaneously and completely by the age of 11 days and had remained well at the age of 1 year. This reinforces the view that reversible congenital nephrotic syndrome does occur and that it is not a single disease with a universally dismal prognosis.
\end{abstract}

Congenital nephrotic syndrome presents in the first three months of life, ${ }^{12}$ and usually results in death in early childhood unless intensive treatment including renal transplantation is undertaken. ${ }^{1-3}$

Only four cases of congenital nephrotic syndrome with spontaneous recovery have previously been reported, and of these two did so at 10 and 25 months. ${ }^{13}$ The other two were siblings whose mother had focal segmental glomerulosclerosis and were presumed to have been affected by humoral factors; they recovered in less than three weeks. ${ }^{4}$ 
Case report

A girl presented at the age of 92 hours with peripheral oedema. She was the first child of a 29 year old white mother; the pregnancy had been uncomplicated, with normal blood pressure, no proteinuria, and she had taken no medication. Family history was unremarkable. She was born at 38 weeks' gestation weighing $2466 \mathrm{~g}$, and the 1 minute Apgar score was 9. The placenta weighed $640 \mathrm{~g}$ and was healthy.

Examination at 12 and 48 hours (because of poor feeding) showed no abnormality. By 92 hours she had only lost $16 \mathrm{~g}$ despite feeding poorly and she had developed oedema of the limbs and around the eyes. Her pulse was $160 / \mathrm{min}$, respiratory rate $40 / \mathrm{min}$, and blood pressure $75 / 49 \mathrm{~mm} \mathrm{Hg}$.

The urine looked clear, but there was gross haematuria and proteinuria on ward testing. There were no casts present. Urinary electrophoresis showed a heavy unselective proteinuria. The plasma protein concentrations were low; total protein was $30 \mathrm{~g} / \mathrm{l}$ (albumin 20 $\mathrm{g} / \mathrm{l}$ and globulin $10 \mathrm{~g} / \mathrm{l}$ ), confirming the diagnosis of nephrotic syndrome. Investigations did not reveal a cause for the congenital nephrotic syndrome; antenatal Veneral Disease Research Laboratory screening for syphilis was negative as were the baby's toxoplasma, rubella, herpes and cytomegalovirus titres. She had a normal female karyotype. Ultrasound scanning showed slight bilateral renal enlargement (kidney length $5.5 \mathrm{~cm}$ ) with poor corticomedullary differentiation and no evidence of hydronephrosis or renal vein thrombosis. Her mother's urinary albumin:creatinine concentration ratio was normal at $1.9 \mathrm{mg} / \mathrm{mmol}$ (upper limit of reference range 3.5 ).

Over the next two days the baby's feeding improved, but she developed increasing oedema, gained $500 \mathrm{~g}$ in weight, and showed clinical signs of intravascular hypovolaemia with strikingly cold peripheries. Biochemical and haematological indices were consistent with hypovolaemia. Her plasma creatinine concentration was normal at $38 \mu \mathrm{mol} / \mathrm{l}$, and the sodium was low at $126 \mathrm{mmol} / \mathrm{l}$. Her urinary sodium was less than $5 \mathrm{mmol} / \mathrm{l}$, and the urine: plasma ratio for urea was greater than 12 giving a value for fractional reabsorption of sodium of at least $99 \cdot 6 \%$. The haemoglobin concentration was 190 g/l.

She was treated with $15 \mathrm{ml} / \mathrm{kg}$ of plasma protein fraction and $2 \mathrm{mg}$ frusemide given intravenously, which resulted in improved peripheral perfusion, a diuresis, and loss of $170 \mathrm{~g}$ in weight, a fall in haemoglobin concentration to $170 \mathrm{~g} / \mathrm{l}$, and correction of her plasma sodium concentration to $144 \mathrm{mmol} / \mathrm{l}$.

Her proteinuria remained (maximal colour on test strip) for three days, then reduced gradually; by day 11 her urine contained no pro- tein, her plasma albumin concentration had risen to $31 \mathrm{~g} / \mathrm{l}$, her oedema had completely resolved, and she was feeding well and gaining weight. A repeat ultrasound scan at 19 days showed kidneys of normal length $(4 \cdot 4 \mathrm{~cm})$ with corticomedullary differentiation. At 1 month a dimercaptosuccinic acid scan was normal. At 1 year she remained completely well, with a urinary microalbumin concentration below the detection limit of the assay $(12 \mathrm{mg} / \mathrm{l})$.

\section{Discussion}

As this baby had proteinuria, hypoproteinaemia, and oedema at 4 days of age, she had by definition got congenital nephrotic syndrome. Renal biopsy was not carried out because of her spontaneous recovery, and no predisposing cause was identified. Only four cases have previously been described in which spontaneous resolution of congenital nephrotic syndrome occurred; in two this was after much longer (10 and 25 months), ${ }^{13}$ and in one of these hypotensive treatment was required initially. ${ }^{3}$ The other two cases were siblings whose mother had focal segmental glomerulosclerosis $^{4}$; the index case's mother had normal urinary protein excretion. All other cases of congenital nephrotic syndrome that have resolved have required treatment with steroids, ${ }^{5}$ or have been infants with congenital syphilis who have been treated with penicillin.

Congenital nephrotic syndrome is associated with various histological patterns, of which the Finnish type is most common. Others include diffuse mesangial sclerosis, focal segmental glomerulosclerosis, and-rarely-a pattern of minimal change seen in infants that have responded to treatment with steroids. ${ }^{2}$ As congenital nephrotic syndrome is usually an irreversible debilitating condition that leads to death unless active treatment is instituted, it is likely that these rare cases that undergo spontaneous remission represent a separate histological subgroup. To our knowledge this girl had the earliest spontaneous recovery yet described. Her case reinforces the view that reversible congenital nephrotic syndrome does occur, and that congenital nephrotic syndrome is not a single disease with a universally dismal prognosis.

1 Mahan JD, Mauer SM, Sibley RK, Vernier RL. Congenital nephrotic syndrome: evolution of medical management and results of renal transplantation. $\mathcal{F}$ Pediatr 1984;105:549-57.

2 Mahan JD, Hoyer JR, Vernier RL. Nephrotic syndrome in the first year of life. In: Cameron S, Glassock R, eds. The nephrotic syndrome. New York: Marcel Dekker, 1988. 401-22.

3 Anand SK, Northway JD, Verniern RL. Congenital nephrotic syndrome: report of a patient with cystic tubular changes who recovered. $f$ Pediatr 1979;95:265-8.

4 Lagrue G, Niaudet $P$, Guillot F, Lang P. Pregnancy and glomerulonephritis. Lancet 1989;ii:1037.

5 Bensman A, Sinnassammy P. Congenital nephrotic syndrome. F Pediatr 1984;107: 157. 